\title{
Theoretical Analysis on the Effect of Surface Horizontal Traction on Top-Down Cracking of Flexible Pavement
}

\author{
Zainab Ahmed Alkaissi ${ }^{1}$, Yasir M. Al-Badran ${ }^{2}$, and Najwa Wasif ${ }^{3, *}$ \\ ${ }^{1}$ Department of Highway and Transportation Engineering, Mustansiriyah University, Baghdad, Iraq, zainabalkaisi77@googlemail.com, \\ dr.zainabalkaissi77@uomustansiriyah.edu.iq \\ ${ }^{2}$ Department of Highway and Transportation Engineering, Mustansiriyah University, Baghdad, Iraq \\ ${ }^{3}$ Department of Highway and Transportation Engineering, Mustansiriyah University, Baghdad, Iraq, najwawasif77@uomustansiriyah.edu.iq \\ *Corresponding author: NajwaWasif,najwawasif77@uomustansiriyah.edu.iq \\ Published online: 31 March 2019
}

Abstract-Fatigue cracking of flexible pavement is one of the most important elements that should be considered due to the damage occurs in asphalt layer under the effect of wheel load repetitions. This research demonstrated theoretical study on top-down fatigue crackingusing the finite element method. A threedimensional finite elastic structural element is used to modal pavement using (ABAQUS ver. 6.12.1) program. The results obtained from this studydemonstrated that maximum value of tensile strain developed at the surface of asphalt layer for flexible pavement due to the horizontal traction generated from wheel load application at contact area. Also, the horizontal tensile strain $\left(\varepsilon_{x x}\right)$ at surface of asphalt layer is increasing rapidly with load repetitions with values greater than that generated at bottom by $(94 \%)$ at failure. This prescribed the basic or inherent features of top crack initiation and down propagates within asphalt layer in flexible pavement. The top horizontal tensile strains obtained from the finite element model is higher than the empirical relations by (20\%); since the finite element analysis of flexible pavement considered the surface horizontal tensile strains due to contact traction force at tire pavement interface. Finally, according to the results of this study the horizontal tensile strains at the top of asphalt surface significantly increase the damage intensity of fatigue failure for flexible pavement.

Keywords - Fatigue Damage, Finite Element. Flexible Pavement, Tensile Strain, Top -Down Cracking.

\section{Introduction}

The cracking of flexible pavement occurs when the horizontal tensile strain exceed the allowable limits. Fatigue cracking is associated with critical tensile strain developed in asphalt layer under the application of moving wheel load. The aim of this research is to simulate the fatigue damage through estimating the critical tensile strains produced at the bottom and top of asphalt layer within flexible pavement using the finite element methods which considered as one of the powerful techniques used in several engineering problems. In the finite element model of pavement structure, the horizontal, vertical, normal and shear stresses can be computed.

Behiry (2012) studied the effect of increasing axle load and variation of pavement modulus on the overall pavement life. The results showed that tensile and compressive strain increased with increasing axel loads anddecreased with increasing asphalt layer modulus [2]. Jill et al, (2003) performs a three-dimensional finite element using ABAQUS program to estimate the stresses in flexible pavement systems with present transverse crack [3]. It was demonstrated that the existing of transverse crack increase significantly the vertical stress in the base layer and also it's has significant effect on the horizontal stresses in the asphalt layer.

Zhengetal. (2017) provides an experimental investigation on the fatigue performance of flexible pavement with high modulus asphalt concretes including the cycles of stressstrain test and direct tensile fatigue test. The modified Neuber equation and local stress- strain method is used to predict the initiation of fatigue crack life of hot mix asphalt concrete pavement [8]. 


\section{Finite Element Modeling for Pavement}

For modeling of fatigue damage of flexible pavement to emphasize the objectives of this research, threedimensional finite elastic solid continuum element of pavement using element (C3D8R). The finite element mesh for pavement layers is shown in Figure (1) with fines at the top and contact interface where large horizontal, vertical stress and strains are developed under the applied tire pressure. The finite element model including asphalt layer (100 mm thickness) and subgrade soil $(3000 \mathrm{~mm}$ thickness). To eliminate the effect of boundary due to the fixed boundary that used to simulate the boundaries of the model, suitable dimensions of the model in longitudinal and transverse direction to the applied load is considered as (3600x 6000) $\mathrm{mm}$.

The tire pressure simulated by ABAQUS finite element model using the rectangle shape shown in Figure (2) which assumed that the standard axel load of one tire of $(40 \mathrm{kN})$ is transferred to pavement surface through uniform contact pressure of ( $690 \mathrm{kPa}$ ) with neglecting the stiffness effect of tire wall, the contact pressure will equal to tire pressure [3].

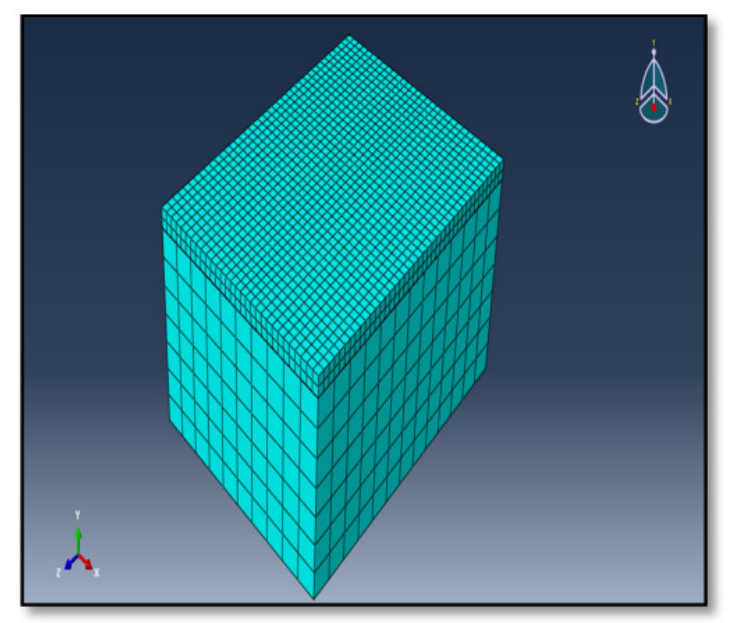

Figure 1: Finite Element Mesh of Pavement Model

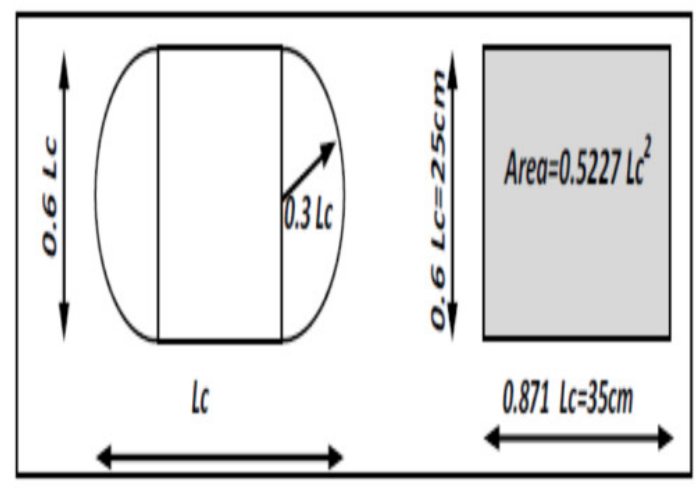

Figure 2: Contact Area of Tire Pressure [4]

To determine the fatigue damage of wheel load on the flexible pavement, moving load that varies in space and time has been simulated in this research using ABAQUS computer program through the application of Load Module.

The step loading is divided into 8 steps (to complete one cycle)as shown in Figure (3) to simulate the moving repeated loading on the surface of flexible pavement using the application of Step Module.Also Figure (3) presents the boundary conditions for pavement geometry model which is fixed at the bottom of subgrade soil layer ( no vertical and horizontal movements) and the edges parts of pavement model fixed in all directions except for vertical directions.

The Interaction Module is applied to simulate the contact surfaces and integration between asphalt layer and foundation layer (ABAQUS Theory Manual, 2009) [1]as shown in Figure (4).

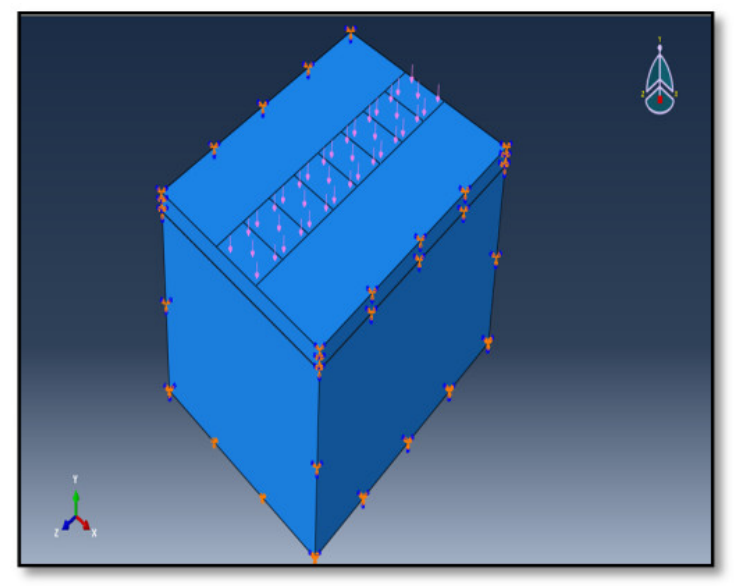

Figure 3: Moving Load for 3D Pavement Model using Step Module

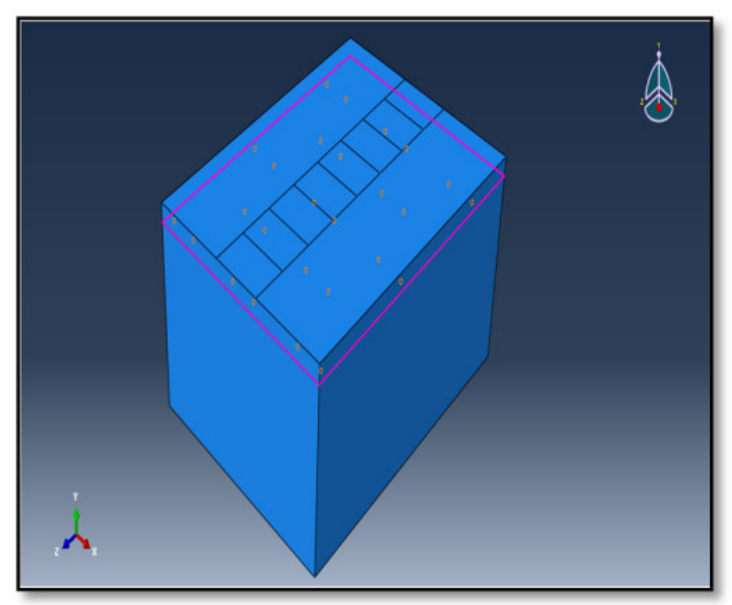

Figure 4: Interaction of Pavement Model using Interaction Module

The characterization for layer materials are presented in Table (1) which have used as input for the finite element program for flexible pavement model. 
Table 1: Pavement Layer Properties [5] and [6]

\begin{tabular}{|c|c|c|c|}
\hline $\begin{array}{c}\text { Pavement } \\
\text { Layers }\end{array}$ & $\begin{array}{c}\text { Elastic } \\
\text { Modulus } \\
(\mathbf{M P a})\end{array}$ & $\begin{array}{c}\text { Poisson's } \\
\text { ratio (v) }\end{array}$ & $\begin{array}{c}\text { Density } \\
\left(\mathbf{K g} / \mathbf{m}^{\mathbf{3}}\right)\end{array}$ \\
\hline Asphalt & 508 & 0.35 & 2240 \\
\hline $\begin{array}{c}\text { Local Subgrade } \\
\text { Layer }\end{array}$ & 211.53 & 0.4 & 1870 \\
\hline
\end{tabular}

\section{Results and Discussions}

\subsection{Stresses and Strains Distributions in Flexible Pavement}

One of the most primary considered element in the design of flexible pavement are the stresses and strains generated in pavement layer and interfaces due to the application of wheel loads repetitions. The obtained results of stress and strain distributions from the finite element pavement model used in this research by (ABAQUS) are displayed and discussed in sections below.

For a specific interest of the fatigue failure phenomena in flexible pavement which considered as major problems in pavement design that related to repetitions of loading; a considerable interest for the horizontal tensile stress and strains at the asphalt layer are considered.

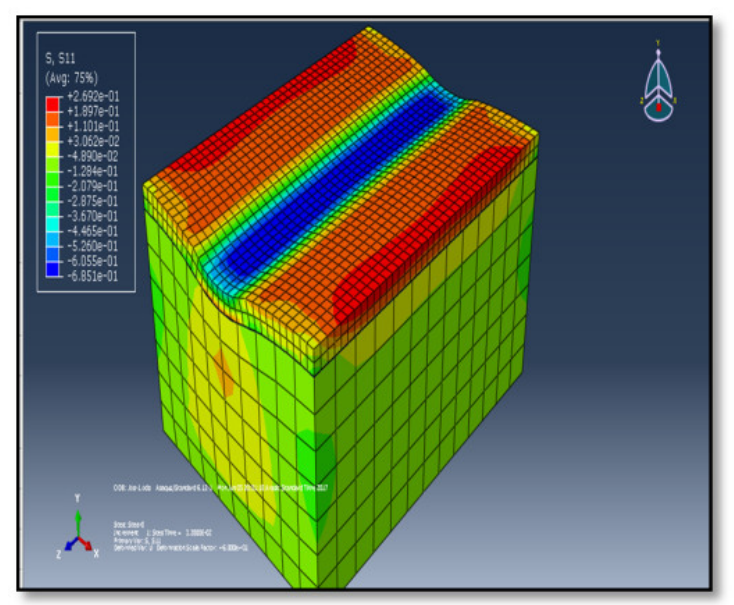

Figure 5: Horizontal Stress $\left(\sigma_{\mathrm{xx}}\right)$ Distribution within Pavement Layers

\subsection{Effect of Load Application on Horizontal Stress Distributions}

As displayed in Figure (5) for the distribution of horizontal stresses $\left(\sigma_{\mathrm{xx}}\right)$ in pavement system as general and asphalt layer as particular.

A maximum tensile horizontal stresses $\left(\sigma_{\mathrm{xx}}\right)(645 \mathrm{kPa})$ is concentrated on the top of asphalt layer under the tire print interaction area which is about $(93.5 \%)$ of applied tire pressure $(690 \mathrm{kPa})$ but reduced to about $(48 \mathrm{kPa})$ which is about $7.3 \%$ of applied pressure then change rapidly and becomes compressive stresses within subgrade layer were a value of $(110 \mathrm{kPa})$ is obtained which is about $(16 \%)$ of applied tire pressure. Increasing depth below pavement show rapid decrease of generated stresses. The tensile response of stresses immediately underneath the loaded wheel load may be considered as a critical response for fatigue cracking (top-down cracking) in flexible pavement surfaces.
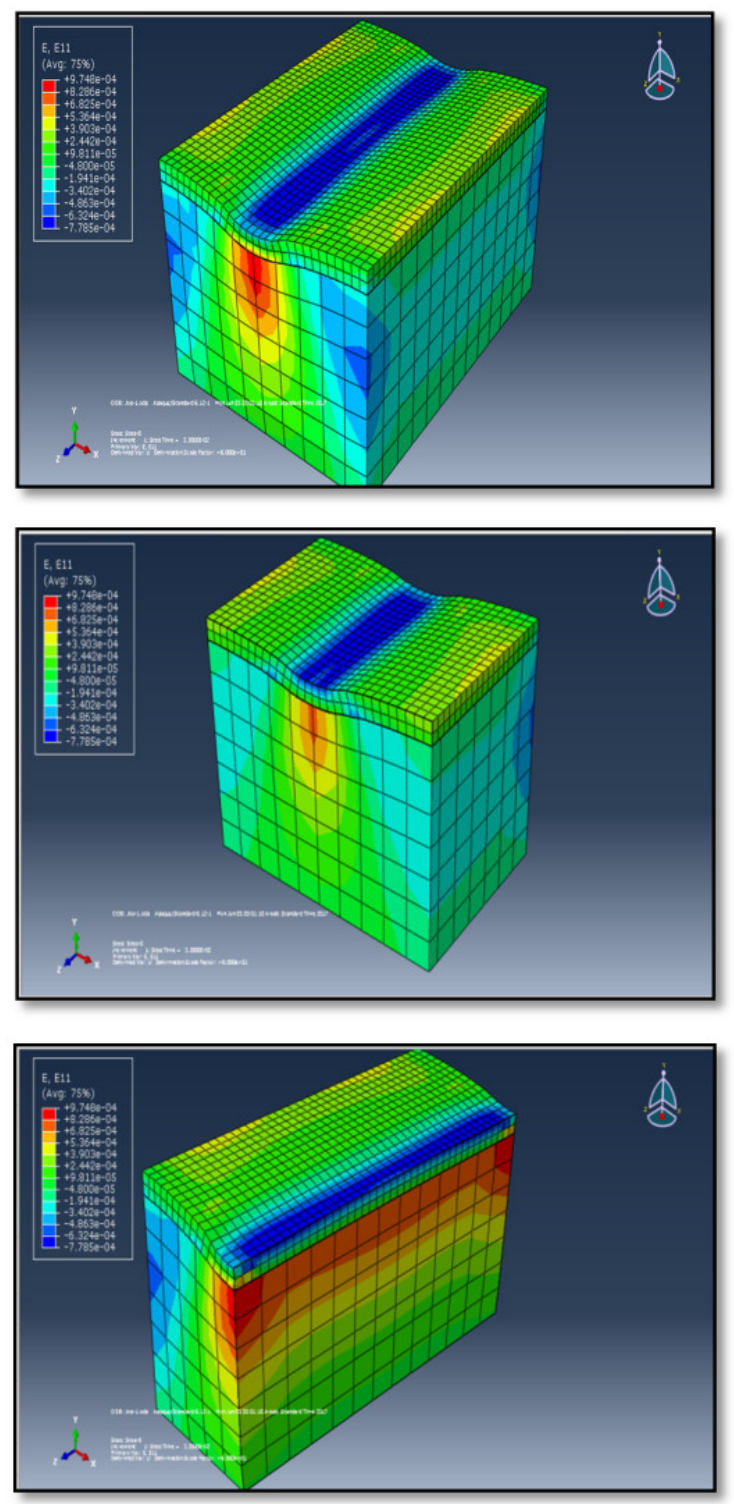

Figure 6: Horizontal Strains ( $\varepsilon_{\mathrm{xx}}$ ) Distribution within Pavement Layers

\subsection{Effect of Load Application on Horizontal Stress Distributions}

Conventionally most pavement design models are based on horizontal strain value at bottom of asphalt layer to predict the performance of flexible pavement.Figure (6) illustrated the distribution of horizontal strain $\varepsilon_{\mathrm{xx}}$ within pavement layers. Maximum value of tensile strain developed at the surface of asphalt layer for flexible pavement due to the horizontal traction generated from wheel load application at contact area. As observed from the obtained results the horizontal tensile strains at surface 
of asphalt layer under the wheel load application is higher than at bottom of asphalt layer. This demonstrated the influence of higher tensile strains at surface on fatigue topdown cracking. These tensile strains extend through the pavement depth until the bottom of asphalt layer then change to compressive strain at the top of subgrade layer.

\subsection{Effect of Load Repetitions}

Generally the fatigue cracking is related to tensile strain developed within asphalt layer surface and bottom. In this research the top (surface) tensile strain is estimated and compared to that at bottom as shown in Figure (7) below taking into consideration the effect of load repetitions of applied wheel load.

It can be observed from the obtained results; the horizontal tensile strain $\left(\varepsilon_{\mathrm{xx}}\right)$ at surface of asphalt layer is increasing rapidly with load repetitions with values greater than that generated at bottom by $(94 \%)$ at failure. This prescribed the basic or inherent features of top crack initiation and down propagates within asphalt layer in flexible pavement.

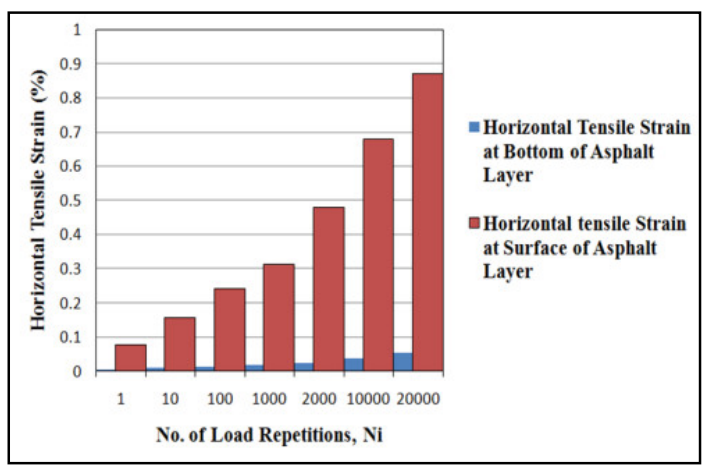

Figure 7: Effect of Load Repetitions on Horizontal

Tensile Strains $\left(\varepsilon_{\mathrm{xx}}\right)$

\section{Fatigue Cracking of flexible Pavement}

Flexible pavements exhibit fatigue cracking when the horizontal tensile strain exceed certain limits. Thefatigue failure criteria suggested by Asphalt Institute (MS-1, 1982) have been used which relate the tensile strain on the bottom of asphalt layer with design life of pavement:

$\mathrm{N}_{\mathrm{f}}=0.0796\left[\left(\frac{1}{\epsilon_{\mathrm{t}}}\right)\right]^{3.291}\left(\frac{1}{\mathrm{E}_{1}}\right)^{0.854}$

$N_{f}$ : Number of load repetitions to cause fatigue cracking.

$\epsilon_{\mathrm{t}}$ : Tensile strain at the bottom of asphalt layer.

$E_{1}$ : Elastic modulus of asphalt layer (psi).

Figure (8) illustrated the results for number of load repetitions to cause fatigue cracking of $\mathrm{N}_{\mathrm{f}}$ flexible pavement based on finite element program and empirical relation. It can be depicted that the finite element results underestimate for $\mathrm{N}_{\mathrm{f}}$ as compared with empirical relation.

This is due to that the finite element model takes into consideration the tensile strain for the top tensile strain of asphalt layer within flexible pavement which results in minimum design pavement life.

Where empirical relation based on bottom tensile strain of asphalt layer only. This confirm the objectives of this research that illustrated the significant effect of tensile strain on the top of asphalt surface under the applied wheel load on fatigue cracking failure of flexible pavement.

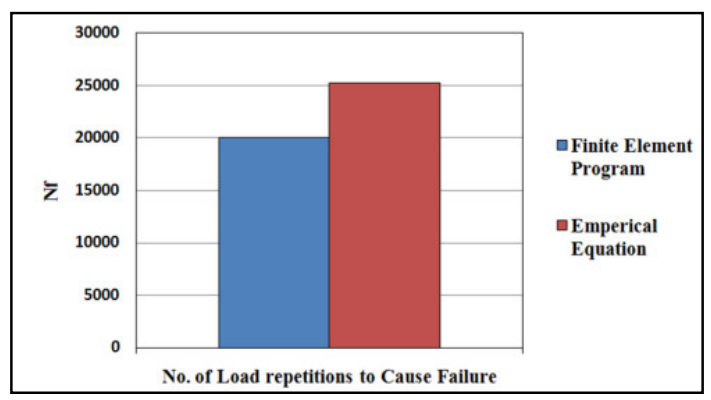

Figure 8: Number of Load Repetitions to Cause Fatigue Failure of Flexible Pavement

Due to the application of repeated load on a fatigue damage $\mathrm{D}_{\mathrm{i}}$ of flexible pavement will produced; which estimated from Eq.2 below (Huang, 2004):

$\mathrm{D}_{\mathrm{i}}=\frac{1}{\mathrm{~N}_{\mathrm{i}}}$

Figure (9) presents the fatigue damage of flexible pavement due to the repetitions of wheel load based on the results of finite element model and empirical equation.

The damage due to top surface cracking using the finite element model is higher than the empirical relations by $(20 \%)$ as a percentage value; since the finite element model of flexible pavement considered the surface horizontal tensile strains due to contact traction force at tire pavement interface and this demonstrated that the additional of horizontal tensile strains at top of asphalt surface significantly increase the damage intensity of fatigue failure for flexible pavement.

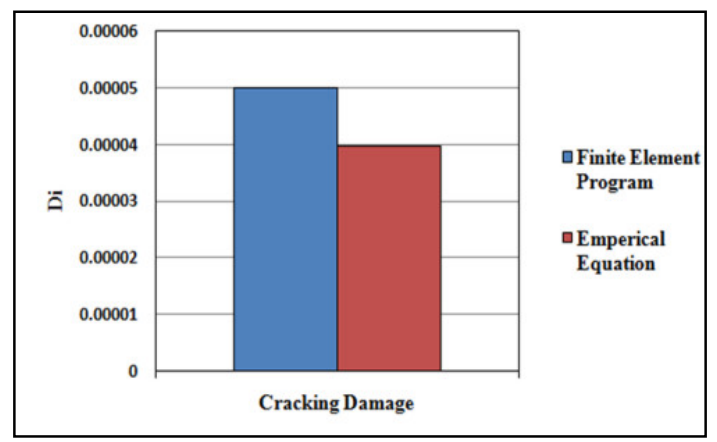

Figure 9: Cracking Damage of Flexible Pavement

\section{Conclusions}

This research illustrated a theoretical study on the fatigue damage of flexible pavement under repeated wheel load. The following concluding remarks can be drawn: 
1. A maximum tensile horizontal stresses $\left(\sigma_{\mathrm{xx}}\right)$ is concentrated on the top of asphalt layer under the tire print interaction area which is about $(93.5 \%)$ of applied tire pressure but reduced to about $(7.3 \%)$ of applied pressure then change rapidly and becomes compressive stresses within subgrade layer were a value of $(16 \%)$ is obtained.

2. The tensile response of stresses immediately underneath the loaded wheel load may be considered as a critical response for fatigue cracking (top -down cracking) in flexible pavement surfaces.

3. Maximum value of tensile strain developed at the surface of asphalt layer for flexible pavement due to the horizontal traction generated from wheel load application at contact area.

4. The horizontal tensile strain $\left(\varepsilon_{\mathrm{xx}}\right)$ at surface of asphalt layer is increasing rapidly with load repetitions with values greater than that generated at bottom by $(94 \%)$ at failure. This prescribed the basic or inherent features of top crack initiation and down propagates within asphalt layer in flexible pavement.

5. The damage due to top surface cracking of flexible pavement using the finite element model is higher than the empirical relations by $(20 \%)$ as a percentage value; since the finite element model of flexible pavement considered the surface horizontal tensile strains due to contact traction force at tire pavement interface.

6. The horizontal tensile strains at the top of asphalt surface significantly increase the damage intensity of fatigue failure for flexible pavement.

\section{Refrences}

[1] Abaqus Theory Manual, Version, (2009), Hibbitt, Karlsson and Sorenson, Inc., INC.

[2] Behiry, A (2012):" Fatigue and rutting lives in flexible pavement". Ain Shams Engineering Journal, Ain Shams University, Vol.3, pp. 376-347.

[3] Huang, Y. H. (2004): "Pavement Analysis and Design", 2nd edition, Prentice Hall, Englewood Cliffs, New Jersey.

[4] Jill, et.al. (2003):" Investigation of Factors to Surface Initiated Cracks in Flexible Pavements". Department of Civil Engineering, University of Minnesota, Minnesota Local Road Research Board, Report No. $\mathrm{MN} / \mathrm{RC}-2003-07$.

[5] Masood, G. (2013):" Experimental and Numerical Investigation of Stabilized Unbounded Granular Pavement Materials". Msc. Thesis, Highway and Transportation Department, Al-Mustansiriyah University.

[6] Khalil, S. (2010): "Mechanistic Empirical Design of Flexible Pavement". Msc. Thesis, Civil Engineering Department, University of Baghdad.

[7] Zheng, et.al. (2017):" Fatigue Life Prediction of High Modulus Asphalt Concrete Based on theLocal StressStrain Method". Applied Science journal, Vol. 7, 305, 2017.

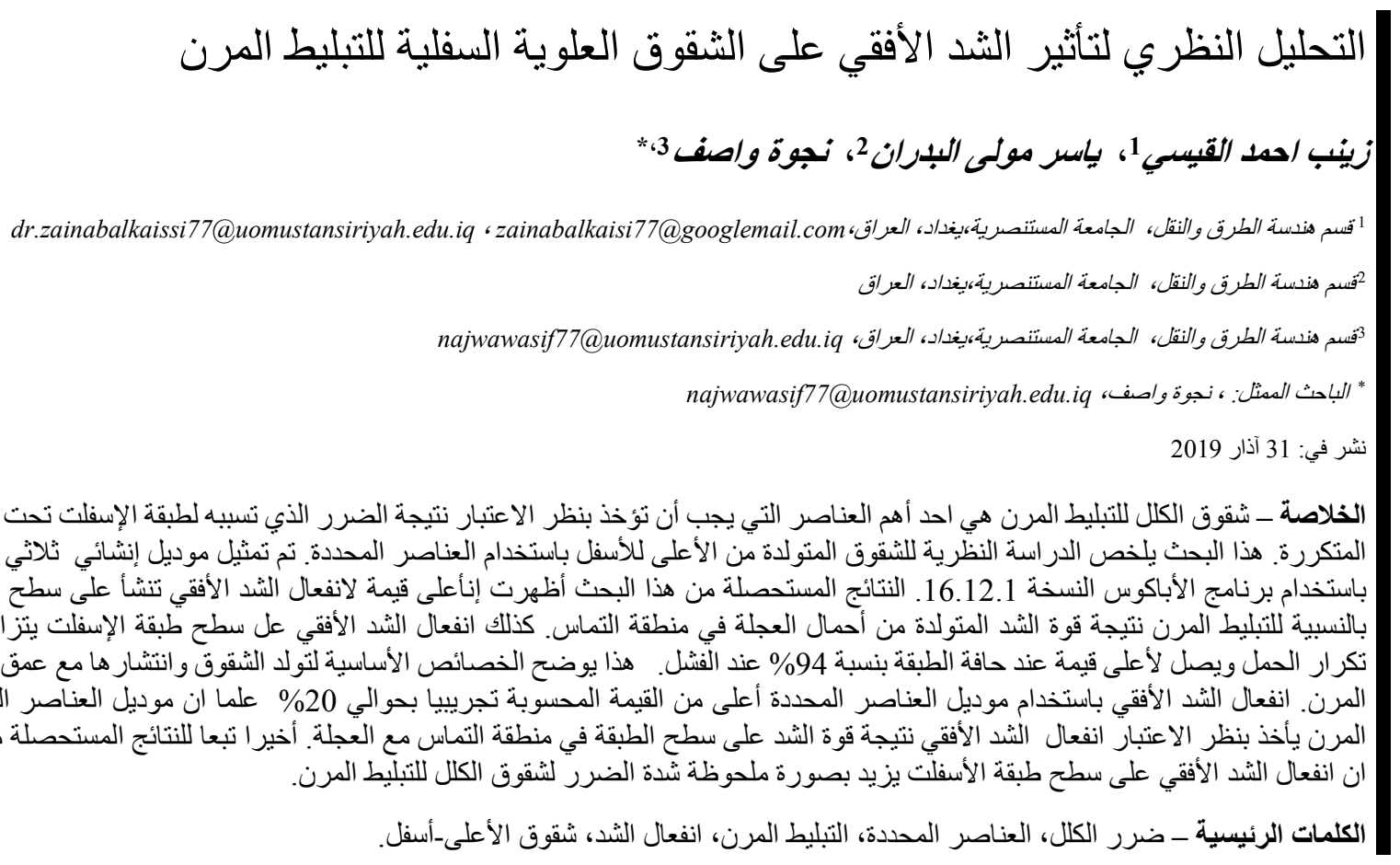

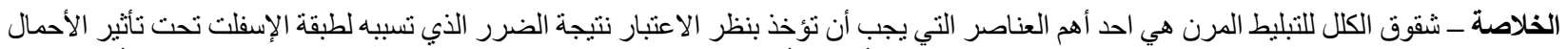

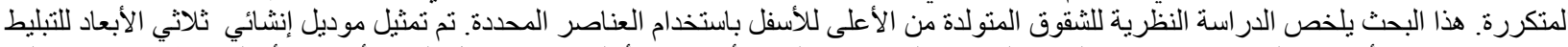

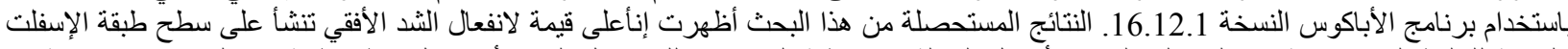

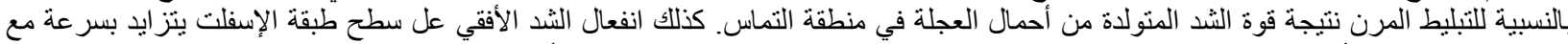

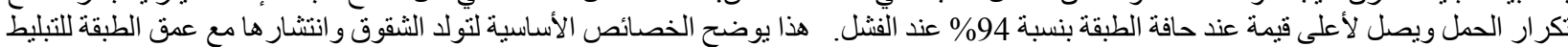

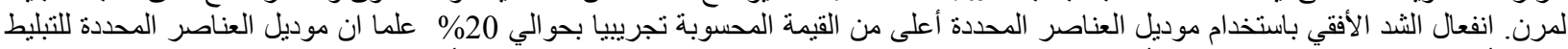

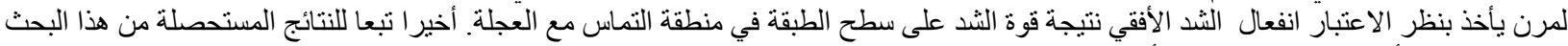
الكلمات الرئيسية - ضرر الكلل، العناصر المحدة، التبليط المرن، انفعال الثد، شقوق الأعلى_أسفل. 